\title{
PENGARUH PENGGUNAAN ALAT KONTRASEPSI IUD DAN SUNTIK TERHADAP SIKLUS HAID DIWILAYAH KERJA PUSKESMAS TAMALANREA JAYA KOTA MAKASSAR
}

\author{
Suhartatik $^{1}$, Amriati Mutmainna ${ }^{2}$ \\ ${ }^{1}$ STIKES Nani Hasanuddin Makassar \\ ${ }^{2}$ STIKES Nani Hasanuddin Makassar \\ Alamat Koresponden : (nurhaisah96@gmail.com/081343374027)
}

\begin{abstract}
ABSTRAK
Menstruasi atau haid adalah perdarahan secara periodik dan siklus dari uterus, disertai pelepasan atau deskuamasi endometrium yang terjadi setiap bulan secara teratur pada wanita dewasa dan sehat. Panjang siklus haid ialah jarak antara tanggal mulainya haid lalu dan mulai haid berikutnya. Penelitian ini bertujuan untuk mengetahui pengaruh penggunaan alat kontrasepsi suntik dan IUD terhadap siklus haid antara pengguna kontrasepsi IUD dan kontrasepsi suntik dan untuk mengetahui pengaruh kedua alat kontrasepsi ini terhadap siklus haid Diwilayah Kerja Puskesmas Tamalanrea Jaya Kota Makassar. penelitian ini menggunakan Teknik pengambilan sampel adalah dekskriptif analitik dengan pendekatan cross sectional study. Yaitu suatu penelitian yang mempelajari dinamika korelasi antara faktor-faktor resiko dengan efek dengan cara pendekatan observasi pada saat pengumpulan data ,jumlah sampel 55 orang. Data dianalisis dengan menggunakan teknik statistik untuk uji chi-square. Dari hasil uji statistic di peroleh dengan nilai $\rho$ $=0,037$. Dengan demikian nilai $\rho>a(0,05)$. Karena nilai $p$ lebih kecil dari $\rho<a(0,05)$ Maka dapat disimpulkan bahwa $\mathrm{HO}$ ditolak dan $\mathrm{Ha}$ di terima. Ada pengaruh penggunaan alat kontrasepsi IUD dan Suntik terhadap siklus haid diwilayah kerja puskesmas tamalanrea kota Makassar.
\end{abstract}

Kata Kunci: Alat Kontrasepsi, IUD, Siklus Haid, Suntik

\section{PENDAHULUAN}

Menurut WHO, Pemilihan alat kontrasepsi berpengaruh terhadap angka terjadinya kehamilan, IUD merupakan pilihan kontrasepsi yang efektif, aman, dan nyaman digunakan bagi sebagian wanita karena IUD merupakan metode kontrasepsi reversibel yang paling sering digunakan di seluruh dunia dengan pemakaian mencapai sekitar 100 juta wanita. Generasi terbaru IUD memiliki efektivitas lebih dari 99\% dalam mencegah kehamilan pada pemakaian satu tahun atau lebih. Pemakaian IUD terhadap penurunan fertilitas mempunyai efektifitas yang cukup tinggi. Risiko kegagalan IUD khususnya CuT380A sebanyak $0,8 \%$ tiap 100 wanita bahkan bisa 1:170 wanita pada pemakaian tahun pertama (Panggih, 2017).

Persentase peserta KB aktif terhadap pasangan usia subur di Indonesia pada tahun 2016 sebesar 74,8\%. Tiga provinsi yang memiliki persentase tertinggi yaitu Maluku Utara sebesar 87,03\%, Kepulauan Bangka Belitung sebesar $83,92 \%$, dan Sulawesi Utara sebesar 83,84\%. Sedangkan capaian terendah terdapat di Provinsi Nusa Tenggara Timur sebesar 63,24\%, Sumatera Barat sebesar 63,73\%, dan DKI Jakarta sebesar 67,46\% (Kementerian Kesehatan RI, 2017).
Berdasarkan data dari Dinas Kesehatan Prov. Sulsel, persentase dapat dilihat bahwa Kabupaten/Kota dengan persentase peserta KB baru tertinggi ialah Kabupaten Gowa (76,14\%), kemudian Palopo (15,50\%), dan Pinrang (13,31\%). Sedangkan Kabupaten/ Kota dengan persentase peserta KB baru terendah ialah Kabupaten Jeneponto $(1,25 \%)$, Kabupaten Bulukumba (0\%), dan Kabupaten Takalar $(0 \%)$. Tingkat provinsi persentase peserta KB baru pada tahun 2016 di Sulawesi Selatan adalah sebesar $13,80 \%$. Sedangkan pada peserta KB baru, persentase metode kontrasepsi yang terbanyak digunakan adalah suntikan, yakni sebesar $61,85 \%$. Metode terbanyak kedua adalah pil, sebesar $23,70 \%$. Metode yang paling sedikit dipilih oleh para peserta KB baru adalah metode AKDR IIUD sebanyak $11,07 \%$, metode operasi pria (MOP) sebanyak $0,07 \%$, kemudian metode operasi wanita (MOW) sebanyak 0,85\%, dan kondom $(2,64)$ (Dinkes Sulsel, 2017).

Berdasarkan data dari Puskesmas Tamalanrea Jaya Kota Makassar, menunjukkan bahwa jumlah pengguna kontrasepsi aktif pada tahun 2015 sebanyak 1.928 akseptor, meningkat pada tahun 2016 sebanyak 2.437 akseptor dan meningkat lagi pada tahun 2017 sebanyak 2.437 akseptor. Jumlah akseptor yang tercatat dari bulan 
Januari sampai bulan September 2018 sebanyak 2.564 akseptor, dimana IUD sebanyak 94 akseptor, suntik sebanyak 1.010 akseptor, (Data sekunder Puskesmas Tamalanrea Jaya Kota Makassar, 2018). Berdasarkan hasil observasi pada saat pengambilan data awal menunjukkan bahwa kontrasepsi suntik termasuk kontrasepsi yang paling banyak diminati di wilayah kerja Puskesmas Tamalanrea Jaya Kota Makassar padahal kontrasepsi suntik termasuk kontrasepsi yang mempunyai efek samping yang paling banyak dibandingkan kontrasepsi yang lain.

\section{BAHAN DAN METODE}

\section{Desain, Waktu, Pupulasi dan Sampel}

Penelitian ini menggunakan metode penelitian deskriptif analitik dengan pendekatan cross sectional study yaitu suatu penelitian yang mempelajari dinamika korelasi antara faktor-faktor resiko dengan efek, dengan cara pendekatan, observasi atau pengumpulan data sekaligus pada suatu saat (point time approach) (Notoatmodjo, 2014). Penelitian ini telah dilaksanakan di Wilayah Kerja Puskesmas Tamalanrea Jaya Kota Makassar. Populasi adalah kumpulan atau agregat objek/unit analisis kemana generalisasi dirumuskan dan dari mana sampel diambil (Setiawan \& Prasetyo, 2015). Populasi dalam penelitian ini sebanyak 123 akseptor KB suntik dan IUD berada di Wilayah Kerja Puskesmas Tamalanrea Jaya Kota Makassar. Jadi jumlah sampel dalam penelitian ini sebanyak 55 akseptor.

1. Kriteria inklusi

a. Akseptor KB yang berada di Wilayah Kerja Puskesmas Tamalanrea Jaya Kota Makassar.

b. Akseptor KB yang bersedia menjadi responden.

2. Kriteria esklusi

a. Akseptor KB yang tidak kooperatif.

b. Akseptor KB yang tidak bersedia menjadi responden.

\section{Pengumpulan Data}

1. Data primer

Data primer disebut juga data tangan pertama. Data primer diperoleh langsung dari subjek penelitian dengan mengenakan alat pengukuran atau alat pengambilan data. Pengumpulan data primer diperoleh dengan menggunakan lembar observasi yang telah disediakan.

2. Data sekunder

Data sekunder adalah data yang diperoleh lewat pihak lain, tidak langsung diperoleh oleh peneliti dari subjek penelitinya. Pengumpulan data sekunder diperoleh dari buku register Puskesmas Tamalanrea Jaya.

\section{Pengolahan data}

1. Editing

Hasil wawancara atau angket yang diperolehkan atau dikumpulkan melalui kuesioner perlu disunting (edit) terlebih dahulu. Kalau tenyata masih ada data atau informasi yang tidak lengkap dan tidak mungkin dilakukan wawancara ulang, maka kuesioner tersebut dikeluarkan (drop out).

2. Coding sheet (membuat lembaran kode atau kartu kode).

Lembaran atau kartu kode adalah instrument berupa kolom untuk merekam data secara manual. Lembaran atau kartu kode berisi nomor responden, dan nomornomor pertanyaan.

3. Data entry (memasukan data)

Yakni mengisi kolom atau kotak lembar atau kartu kode sesuai dengan jawaban masing-masing pertanyaan.

4. Tabulasi

Yakni membuat tabel-tabel data, sesuai dengan tujuan penelitian atau yang diinginkan oleh peneliti (Notoatmodjo, 2014).

\section{Analisa data}

1. Analisa univariat

Analisa univariat bertujuan untuk menjelaskan atau mendeskripsikan karakteristik setiap variabel penelitian. Bentuk jenis analisis univariat tergantung dari jenis datanya. Pada umumnya dalam analisis ini menghasilkan distribusi frekuensi dan persentase dari tiap variabel (Notoatmodjo, 2014).

2. Analisis bivariat

Apabila telah dilakukan analisa univariat akan diketahui karakteristik atau distribusi setiap variabel, dan dapat dilanjutkan analisis bivariat. Analisis bivariat yang dilakukan terhadap dua variabel yang diduga berhubungan atau berkorelasi (Notoatmodjo, 2014). Analisis bivariat menggunakan software SPSS 20 dengan tingkat kesalahan $\alpha=(0,05)$ menggunakan uji chi-square yang bertujuan untuk melihat hubungan antar variabel.

\section{HASIL PENELITIAN}

1. Analisis Univariat

Tabel 1 Distribusi Responden Berdasarkan Katakteristik Responden di Wilayah Kerja Puskesmas Tamalanrea Jaya Kota Makassar 


\begin{tabular}{|c|c|c|}
\hline Karaktersitik Responden & $\mathrm{n}$ & $\%$ \\
\hline Umur & & \\
$21-25$ & 4 & 7,3 \\
$26-30$ & 23 & 41,8 \\
\hline Pendidikan & & \\
Tidak Sekolah & 5 & 9,1 \\
SD & 15 & 27,3 \\
\hline Pekerjaan & & \\
Tidak Bekerja & 24 & 43,6 \\
PNS & 4 & 7,3 \\
\hline
\end{tabular}

Dari 55 responden, responden yang berumur antara 21-25 tahun sebanyak 4 orang $(7,3 \%)$ berumur antara26-30 tahun sebanyak 23 orang $(41,8 \%)$ berumur $31-35$ tahun sebanyak 17 orang (30,9\%) berumur 36-40 tahun sebanyak 5 orang $(9,1 \%)$ berumur 41-45 tahun sebanyak 6 orang $(10,9 \%)$. Dari 55 responden, terdapat responden pendidkan Tidak Sekolah sebanyak 5 orang $(9,1 \%)$, pendidikan SD sebanyak 15 orang $(27,3 \%)$, pendidikan SMP sebanyak 10 orang $(18,2 \%)$, pendidikan SMA sebanyak 17 orang $(30,9 \%)$, pendidikan S1 sebanyak 8 orang $(14,5 \%) . \quad 55$ responden, terdapa tresponden pekerjaan Tidak bekerja sebanyak24 orang $(43,6 \%)$, pekerjaan PNS sebanyak 4 orang $(7,3 \%)$, pekerjaan SWASTA sebanyak 15 orang $(27,3 \%)$, pekerjaan WIRASWASTA sebanyak 12 orang $(21,8 \%)$.

Tabel 2 Distribusi Responden Berdasarkan Kontrasepsi Yang Digunakan Di Wilayah Kerja Puskesmas Tamalanrea Jaya Kota Makassar

\begin{tabular}{|c|c|c|}
\hline $\begin{array}{c}\text { Kontrasepsi } \\
\text { Yang Digunakan }\end{array}$ & $\mathrm{n}$ & $\%$ \\
\hline Suntik & 40 & 72,7 \\
IUD & 15 & 27,3 \\
\hline
\end{tabular}

Tabel 2 dari total 55 responden, terdapat responden yang menggunakan alat kontrasepsi suntik sebanyak 40 orang $(72,7 \%)$, responden yang menggunakan alat kontrasepsi IUD sebanyak 15 orang $(27,3 \%)$.

Tabel 3 Distribusi Responden Berdasarkan Siklus Haid Di Wilayah Kerja Puskesmas Tamalanrea Jaya Kota Makassar

\begin{tabular}{|c|c|c|}
\hline Siklus Haid & $\mathrm{n}$ & $\%$ \\
\hline 35 hari & 28 & 50,9 \\
21 hari & 27 & 49,1 \\
\hline
\end{tabular}

Tabel 3 dari total 55 responden, terdapat responden dengan siklus haid 35 hari sebanyak 28 orang $(50,9 \%)$, responden dengan siklus haid 21 hari sebanyak 27 orang $(49,1 \%)$.

2. Analisis Bivariat

Tabel 4 Pengaruh Penggunaan Alat Kontrasepsi IUD dan Suntik Terhadap Siklus Haid Di Wilayah Kerja Puskesmas Tamalanrea Jaya Kota Makassar

\begin{tabular}{|c|c|c|c|c|c|c|}
\hline \multirow{2}{*}{$\begin{array}{c}\text { Alat } \\
\text { kontrasepsi }\end{array}$} & \multicolumn{4}{|c|}{ Siklus Haid } & \multicolumn{2}{c|}{ Total } \\
\cline { 2 - 6 } & 35 hari & 21 hari & & \\
\cline { 2 - 6 } & $\mathrm{n}$ & $\%$ & $\mathrm{n}$ & $\%$ & $\mathrm{n}$ & $\%$ \\
\hline Suntik & 24 & 43,6 & 16 & 29,1 & 55 & 100 \\
\hline IUD & 4 & 7,3 & 11 & 20,0 & 55 & 100 \\
\hline Total & 28 & 50,9 & 27 & 49,1 & 55 & 100 \\
\hline \multicolumn{2}{|c|}{$p=0,037$} & \multicolumn{4}{c}{$a=0,05$} \\
\hline
\end{tabular}

Tabel 4 menunjukkan bahwa dari 55 responden terdapat $24(43,6 \%)$ responden yang menggunakan alat kontrasepsi suntik menggunakan alat kontrasepsi suntik dengan siklus haid yang cenderung lebih pendek $16(29,1 \%)$ yaitu 21 hari. Sedangan yang menggunakan alat kontrasepsi IUD sebanyak $4(7,3 \%)$ responden dengan siklus haid normal 35 hari yaitu $11(20,0 \%)$

Dari hasil uji statistic dengan nilai $\rho$ $=0,037$. Dengan demikian nilai $\rho>a(0,05)$. Karena nilai $p$ lebih kecil dari $\rho<a(0,05)$ Maka dapat disimpulkan bahwa $\mathrm{HO}$ ditolak dan $\mathrm{Ha}$ di terima. Ada pengaruh penggunaan alat kontrasepsi IUD dan suntik terhadap siklus haid diwilayah kerja puskesmas tamalanrea kota Makassar.

\section{PEMBAHASAN}

1. Distribusi Frekuensi Berdasarkan Alat Kontrasepsi Yang Digunakan

Menurut hasil dapat dilihat dari tabel 5.4 diketahui bahwa terdapat perbedaan dari masing-masing siklus haid yang dialami oleh responden yang menggunakan alat kontrasepsi IUD. Terdapat $4 \quad(7,3 \%)$ responden yang mempunyai siklus haid normal. Siklus haid yang normal bisa terjadi akibat dari produksi hormone estrogen yang cukup. Siklus haid terjadi akibat pengaruh kerja hormone estrogen yang dimiliki oleh tiaptiap individu. Menurut peneliti pengguna akseptor lebih sedikit karena banyak yang mengatakan jika pemasangan alat kontrasepsi sakit dan mengerikan bagi orang awam dan peneliti juga pernah melihat langsung proses pemasangan IUD menggunakan alat yang memang jika dipasang sangat menyakitkan apalagi dipasang didaerah vagina dan tanpa obat bius, setelah diteliti terdapat adanya pengaruh pemakaian pertama kali menggunakan alat kontrasepsi IUD terhadap siklus haid adalah gangguan 
pada menstruasi,mengalami perdarahan, keputihan , nyeri pada saat menstruasi,dan sering pusing.

Pengaruh alat kontrasepsi IUD terhadap siklus haid yaitu gangguan pada menstruasi, mengalami perdarahan keputihan yang lebih banyak,saat menstruasi lebih nyeri, sering pusing bahkan masalah tentang gangguan pada saat berhubungan intim juga banyak dialami oleh beberapa akseptor,akseptor lain menyebutkan bahwa selama menggunan IUD pernah mengalami ekspulsi keluarnya IUD secara mandiri (Panggih,2017)

Namun berbeda pada responden yang menggunakan alat kontrasepsi suntik terdapat $24 \quad(43,6 \%)$ responden yang menggunakan alat kontrasepsi suntik dengan siklus haid yang cenderung lebih pendek $16(29,1 \%)$ yaitu 21 hari. hal ini disebabkan karna sebagian akseptor pengguna alat kontrasepsi suntik sering mengalami haid yang dating $2 x$ dalam jangka waktu 1 bulan dan secara otomatis siklus haidnya menjadi pendek yaitu 21 hari menurut penliti banyak yang menggunakan alat kontrasepsi suntik karena tidak terlalu sakit dan jangka waktunya juga lama ada yang 3 bulan sekali ada yang sebulan sekali sehingga para akseptor tidak perlu bolak balik lagi untuk mengontrol alat kontrasepsinya walaupun banyak efek samping dari alat kontrasepsi suntik ini tapi peminat akseptornya banyak. Setelah diteliti terdapat pengaruh alat kontrasepsi suntik dengan jangka waktu 3 bulan sekali ada yang tidak mengalami menstruasi hanya flek selama menggunakan alat kontrasepsi suntik

Pengaruh penggunaan alat kontrasepsi suntik terhadap siklus haid yaitu terganggunya pada hormone progesterone dan hormone estrogen kedua hormone dapat mencegah terjadinya ovulasi sehingga dapat mempengaruhi pola haid yang normal menjadi amoenorea, perdarahan ireguler, perdarahan bercak. Semakin lama penggunaan maka jumlah darah semakin sedikit dan bahkan sampai terjadi amonerea (Diah,2017).

Dari hasil uji statistic dengan nilai $\rho=0,037$. Dengan demikian nilai $\rho>a(0,05)$. Karena nilai $p$ lebih kecil dari $\rho<a(0,05)$ Maka dapat disimpulkan bahwa $\mathrm{HO}$ ditolak dan $\mathrm{Ha}$ di terima. Ada pengaruh penggunaan alat kontrasepsi IUD dan suntik terhadap siklus haid diwilayah kerja puskesmas tamalanrea kota Makassar.
Hasil penelitian ini sejalan dengan dengan penelitian jurnal (Ikhwani Ratna, 2017) dengan judul "Perbedaan Pengaruh Penggunaan Alat Kontrasepsi lud Dan Suntik Terhadap Siklus Haid Perempuan Di Kecamatan Marpoyan Damai Pekanbaru" Menurut hasil penelitian diketahui bahwa terdapat perbedaan dari masing-masing siklus haid dan karakteristik haid yang dialami oleh perempuan yang menggunakan alat kontrasepsi IUD dan suntik. Terdapat 94,2\% perempuan pengguna alat kontrasepsi IUD yang mempunyai siklus haid normal. Siklus haid yang normal bisa terjadi akibat dari produksi hormone estrogen yang cukup. Siklus haid terjadi akibat dari pengaruh kerja hormon estrogen yang dimiliki oleh tiap-tiap individu.

Namun berbeda pada perempuan yang menggunakan alat kontrasepsi suntik, siklus haid yang sering terjadi adalah siklus haid yang pendek yaitu kurang dari 28 hari. Terdapat $55(64,70 \%)$ perempuan yang mempunyai siklus haid pendek dan 30 $(35,29 \%)$ perempuan yang mempunyai siklus haid normal. Hal itu disebabkan karena sebagian perempuan pengguna alat kontrasepsi suntik sering mengalami haid yang datang $2 x$ dalam jangka waktu 1 bulan dan secara otomatis siklus menstruasinya menjadi pendek yaitu kurang dari 28 hari. Siklus haid pendek (<28 hari) yang disebabkan oleh pengaruh kerja hormon estrogen. Akibat pengaruh kerja hormon estrogen, maka apabila produksi hormon berlebih akan menyebabkan siklus haid menjadi pendek. Perbedaan bisa terlihat dari masing-masing cara kerja alat kontrasepsi IUD dengan kontrasepsi suntik.

Cara kerja alat kontrasepsi IUD adalah mencegah pembuahan sel telur oleh sperma dan mencegah tertanamnya hasil pembuahan pada selaput lendir rahim. Untuk IUD yang mengandung $\mathrm{Cu}$ cara kerjanya adalah mengganggu pengambilan estrogen endogenous oleh mucosa uterus. Sedangkan cara kerja alat kontrasepsi suntik adalah menekan pengeluaran produksi estrogen.

Dengan diberikan suntikan progesteron, diharapkan jumlah hormon progesteron menjadi lebih banyak dari estrogen. Namun pada saat terjadi menstruasi, hormon estrogen akan memuncak sedangkan hormon progesteron tidak memuncak.

Maka apabila produksi hormon berlebihan akan menyebabkan siklus haid 
menjadi pendek. Selain itu cara kerja alat kontrasepsi suntik adalah: Pertama, Mencegah lepasnya sel telur dari indung telur. Kedua, Mengentalkan lendir mulut rahim, sehingga sperma sulit masuk ke dalam rongga rahim. Ketiga, Menipiskan selaput lendir agar tidak siap hamil. Salah satu penyebab haid tidak teratur adalah perubahan produksi kadar hormon ditubuh. Perbedaan yang terjadi dari efek samping yang ditimbulkan akibat penggunaan alat kontrasepsi IUD dengan suntik sangat terlihat.

Selain siklus haid karakteristik haid dari masing-masing alat kontrasepsi juga sangat terlihat perbedaannya. Pada pengguna alat kontrasepsi IUD karakteristik haid yang menggumpal lebih sering terjadi dibandingkan dengan karakteristik haid yang ditimbulkan dari pemakaian alat kontrasepsi suntik. Terdapat 48 (69,56\%) perempuan pengguna alat kontrasepsi IUD yang mengalami karakteristik haid menggumpal dan karakteristik flekflek/spotting terdapat $21 \quad(30,43 \%)$ perempuan usia subur. Sedangkan pada pemakaian alat kontrasepsi suntik terdapat $50(58,82 \%)$ perempuan yang mengalami karakteristik haid menggumpal dan terdapat $35(41,18 \%)$ perempuan yang mengalami karakteristik haid berupa flekflek/spotting.

Haid didefinisikan sebagai perdarahan pervaginam yang terjadi selama 1 episode setiap siklus dan akan kehilangan darah 40-100 $\mathrm{ml}^{2}$. Menurut hasil penelitian yang telah dilakukan bahwa terdapat $48 \quad(69,56 \%)$ perempuan pengguna alat kontrasepsi IUD yang mengalami haid yang $2 x$ lebih banyak dari haid biasa dan hanya terdapat $21(30,43 \%)$ dari 69 yang mengalami sedikit darah yang dikeluarkan pada saat haid.

Hasil analisis statistik diperoleh $t$ hitung sebesar 2,754 dengan nilai $P$ sebesar 0,008 yaitu kurang dari 0,05 maka Ho ditolak dan Ha diterima. Dan dari nilai rata-rata yang diperoleh, siklus haid pada perempuan yang menggunakan alat kontrasepsi IUD sebesar 22,00.
Sedangkan rata-rata siklus haid pada perempuan yang menggunakan alat kontrasepsi suntik sebesar 19,38.

Berdasarkan hasil penelitian dan pembahasan dapat disimpulkan bahwa terdapat perbedaan siklus haid antara responden yang menggunakan alat kontrasepsi IUD dengan kontrasepsi suntik diwilyah kerja puskesmas tamalanrea jaya kota Makassar. Siklus haid pada akseptor yang menggunakan alat kontrasepsi IUD lebih baik dibandingkan dengan akseptor yang menggunakan alat kontrasepsi suntik yaitu dengan siklus normal 21-35 hari, sedangkan akseptor pengguna alat kontrasepsi suntik mempunyai siklus haid pendek yaitu 21 hari atau 2 kali dalam sebulan.

\section{KESIMPULAN}

1. Ada Pegaruh Penggunaan Alat Kontrasepsi IUD Terhadap Siklus Haid Di Wilayah Kerja Puskesmas Tamalanrea Jaya Kota Makassar.

2. Ada Pengaruh Penggunaan Alat Kontrasepsi Suntik Terhadap Siklus Haid Diwilayah Kerja Puskesmas Tamalanrea Jaya Kota Makassar.

\section{SARAN}

1. Dari hasil penelitian bahwa alat kontrasepsi IUD mempunyai siklus haid yang normal dan efek samping yang sedikit namun pemnasangan IUD ini sangat sakit pengguna alat kontrasepsi ini mampu mengetahui apa saja manfaat dan keuntungan,kerugian dari alat kontrasepsi sehingga lebih banyak lagi penggunanya.

2. Dari hasil penelitian bahwa alat kontrasepsi suntik mempunyai siklus haid yang tidak normal dan dapat membuat rahim menjadi kering bahkan pengguna alat kontrasepsi ini tidak menstruasi begitu banyak peminatnya dan kurangnya informasi tentang alat kontrasepsi suntik bagi pengguna saya harap dapat mengetahui apa saja manfaat kerugian,keuntungan dan efek samping dari berbagai macam alat kontrasepsi.

\section{DAFTAR PUSTAKA.}

Dinkes Sulsel. (2017). Profil Kesehatan Kesehatan Provinsi Sulawesi Selatan Tahun 2016. Makassar: Dinas Kesehatan Sulawesi Selatan.

Kementerian Kesehatan RI. (2017). Profil Kesehatan Indonesia Tahun 2016. Jakarta: Kementerian Kesehatan Republik Indonesia.

Notoatmodjo, S. (2014). Metodologi Penelitian Kesehatan. Jakarta: PT. Rineka Cipta. 
Setiawan, D., \& Prasetyo, H. (2015). Metodologi Penelitian Kesehatan Untuk Mahasiswa Kesehatan. Yogyakarta: Graha IImu.

Panggih, (2017). Gambaran keluhan akibat pemakaian alat kontrasepsi intra uterine device (iud) pada akseptor iud di wilayah kerja puskesmas sempor kabupaten kebumen

Diah, (2017). Hubungan pemilihan alat kontrasepsi pada akseptor kb dengan gangguan haid dipuskesmas kalasan sleman. Yogyakarta 